\title{
Construcción de memoria histórica en ausencia de recuerdos colectivos: cómo acercarse al pasado a través de la literatura
}

El nombre de Leonor Villegas de Magnón, quien renunció a su vida acomodada para participar en los eventos armados de la primera parte del siglo XX y en 1914 fundó la Cruz Blanca Constitucionalista, es más conocido en los Estados Unidos que en México. Con su novela Las rebeldes (2011), Mónica Lavín intenta llenar esta laguna histórica sobre la que el discurso oficial había callado. El texto, basado en la obra autobiográfica de Villegas de Magnón La Rebelde (2004), reevalúa el papel de la mujer en la Revolución Mexicana en ambos lados de la frontera Estados Unidos-México y la transforma de personaje marginado a la protagonista principal de la gesta revolucionaria. En este ensayo se propone un acercamiento a las posibilidades que tiene la literatura para la construcción de nuevos conocimientos sobre el pasado histórico. Las reflexiones se basan en el análisis de la relación entre las dos obras mencionadas con el fin de determinar el papel que tiene la memoria en este proceso.

El interés casi obsesivo por recuperar el pasado que ha sido visible en las sociedades occidentales desde hace varias décadas, fue definido por Andreas Huyssen como una cultura de la memoria. Esta nueva forma de interactuar con la temporalidad puede observarse en todos los ámbitos de la vida social, donde las memorias marginadas se recuperan y se levantan frente a las memorias únicas y homogeneizadas. En el contexto de México, por ejemplo, este fenómeno se manifiesta en el cambio dramático en la percepción de la identidad nacional que tuvo lugar en el país a lo largo del siglo pasado: si a su inicio esta se fundamenta en la premisa de que los mexicanos son una nación mestiza, en los años noventa el gobierno cambia su posición oficial, al declarar que a la identidad mexicana hay que concebirla desde la multiculturalidad étnica (Chorba 2).

En los terrenos de la literatura, los nuevos modos de relacionarse con el pasado se realizan a través de la producción de las novelas históricas que lo revisan y lo desmitifican mediante la reescritura de la Historia, ayudando así a la consolidación de la memoria nacional (Pons 16). En contraste con la épica clásica de corte tradicional, con su apreciación del 
pasado histórico como absoluto y cerrado, la novela histórica reconstruye un pasado histórico en el sentido de que es un pasado contemporaneizado, un tiempo que todavía no ha concluido y que está en proceso de elaboración. Además de su carácter híbrido, que resulta de la integración en su mundo ficticio de materiales con distinto grado de historicidad, uno de los aspectos fundamentales de este modo de escribir sobre el devenir histórico es la subordinación de lo individual y privado a lo colectivo y público, hecho que ofrece la posibilidad a los eventos pretéritos de adquirir una importancia y un matiz histórico por sí solos.

Junto a este fenómeno literario global, que no es una actividad puramente literaria y mucho menos inocente - recordemos los siempre actuales argumentos de Valentín Volóshinov sobre la imposibilidad de un lenguaje ideológicamente neutral -, está la así llamada literatura del yo, donde surgen narraciones testimoniales que abordan el pasado reivindicando memorias comunitarias, familiares y personales. $\mathrm{Al}$ contrario de lo que sucede con la novela histórica, en este tipo de escritura la experiencia del sujeto o del grupo deja ser una noción periférica y se vuelve central. Se ofrece así un espacio público para aquellos sujetos marginados por razones de etnia, sexo o clase social, que no han podido expresarse y cuya voz no ha sido escuchada dentro del canon tradicional. Al materializar sus experiencias mediante el discurso, el sujeto explora, explica, negocia o reafirma su identidad, pero no lo hace de manera desinteresada, sino a través de una empresa de justificación personal. He aquí uno de los rasgos específicos de toda autobiografía, una de las modalidades de la escritura testimonial, cuyo carácter bifronte José María Pozuelo Yvancos explica por la convergencia en el proceso de escritura de un acto de conciencia que inventa y construye un yo, por un lado, y, por el otro, de un acto de comunicación o de autojustificación de una identidad frente a los otros, esto es, ante un lector implícito (211).

En América Latina, las autobiografías han existido siempre, sin embargo se han visto como un género relegado, olvidado y hasta negado. Se las encaja en discursos hegemónicos de cierta época, mas nunca se les adjudica un espacio propio. En su análisis de la escritura autobiográfica en América Latina, Silvia Molloy define este género así:

La autobiografía es siempre una re-presentación, esto es, un volver a contar, ya que la vida a la que supuestamente se refiere es, de por sí, una suerte de construcción narrativa. La vida es siempre, necesariamente, relato: relato que nos contamos a nosotros mismos, como sujetos, a través de la rememoración; relato que oímos contar o que leemos, cuando se trata de vidas ajenas. Por lo tanto, decir que la autobiografía es el más referencial de los géneros - entiendo por referencia un 
remitir ingenuo a una "realidad", a hechos concretos y verificable - es, en cierto sentido, plantear mal la cuestión. La autobiografía no depende de los sucesos sino de la articulación de esos sucesos, almacenados en la memoria y reproducidos mediante el recuerdo y su verbalización. (15-16)

Estas esclarecedoras palabras ponen de manifiesto que escribir la autobiografía en América Latina - como en cualquier otra parte del mundo, cuando el que escribe lucha para formar su identidad desde una subjetividad amorfa -, es hacer ejercicio de memoria. En esta acción de exhibir su yo, el que rememora y plasma en papel sus propias experiencias - sean estas íntimas o públicas -, es un yo desdoblado por el acto de la memoria en un yo que recuerda y que se constituye a través del acto de escribir sobre el yo que fue. Una postura muy cercana es la que mantiene Paul John Eakin cuando argumenta que la autobiografía debe entenderse como amalgama de dos artes, el de la memoria y el de la imaginación: "Autobiography in our time is increasingly understood as both an art of memory and an art of imagination; indeed, memory and imagination become so intimately complementary in the autobiographical act that it is usually impossible for autobiographers and their readers to distinguish between them in practice" (5-6). La reflexión sobre muchos aspectos existentes de carácter teórico y empírico que hermanan la novela histórica y la autobiografía excedería los límites de este ensayo. Lo que nos interesa explorar aquí es la capacidad que poseen estos géneros para volver el pasado contemporáneo al presente y determinar de qué manera los textos literarios se convierten en una forma subversiva y de resistencia cultural, capaz de transmitir aquello que de manera voluntaria o intencional se quiere ocultar, silenciar, manipular o "desmemorizar". Para ello, se propone una lectura analítica e interpretativa de dos obras literarias: una es de autoría de Leonor Villegas de Magnón que se titula La Rebelde, y la otra es de la pluma de Mónica Lavín, una escritora mexicana contemporánea, quien con su novela Las rebeldes intenta crear la memoria histórica, entendida aquí como "una memoria prestada, aprendida, escrita, pragmática, larga y unificada" (Candau 57).

REBELDES FUERON TODAS

Profundamente patriarcal, la historia oficial mexicana ha prestado poca atención a las aportaciones de las mexicanas a los hechos revolucionarios, constituyendo la descripción de las fases de las batallas el objeto privilegiado de sus estudios. En el arte, donde la existencia de numerosas obras literarias, pictóricas, musicales y cinematográficas sobre este tópico es innegable, la situación es distinta, aunque en ellas el sector femenino 
que más se destaca es el de las mujeres de la clase baja, principalmente rural, que se conoce como las soldaderas. De ellas Claudia Schaefer dice que fueron mitificadas por la sociedad que ha creado sobre esas mujeres revolucionarias una imagen melodramática: recibían órdenes fielmente, concebían y daban a luz en el campo de batalla, y seguían a sus hombres sin dudar y colaborando en cualquier lugar. María del Rocío Oviedo y Pérez de Tudela, al analizar la realidad histórica y los elementos ficcionales en la narrativa sobre la Revolución Mexicana, observó el interés que provocaba la figura de la soldadera en cronistas extranjeros de la época; en sus testimonios estos se referían a ellas como mujeres heroicas que acompañan al ejército, calificando su destino como conmovedor. Oviedo proporciona algunos pasajes de las obras de Edith O’Shaughnessy, una periodista, guionista y escritora norteamericana, quien documentó su opinión sobre las soldaderas en diferentes escritos históricos: "Son el único avituallamiento visible de los combatientes y la abnegación con que van por la vida es sorprendente. $Y$ así siguen las pobres bestias hasta que mueren en el camino, para elevarse finalmente al cielo" (160). La que enaltece a estas mujeres aún más, es Rose Eleanor King, una empresaria inglesa. Siendo dueña del hotel Bellavista en Cuernavaca, conoció a muchos personajes clave de la política mexicana. Ella experimentó la Revolución del lado de los federales, llegó a admirar a las soldaderas, sobre las que da su favorable testimonio:

Mis respetos para las mujeres mexicanas de esta clase. ... Las mujeres que marchaban junto al soldado mexicano, que se adelantaban al lugar donde éste acamparía para tener listo el refrigerio, que lo atendían en la enfermedad y lo confortaban cuando iba a morir, fueron asistentes e intérpretes, cumplieron su parte en la consolidación del actual gobierno liberal. (Oviedo 16o)

Apelativos como adelitas, soldaderas o compañeras de los Juanes, utilizados con frecuencia para referirse a las féminas que seguían a sus compañeros en el combate - aunque muchas veces ellas mismas se autocalificaban como "muy perras" - les negaron a estas mujeres su papel de luchadoras conscientes que por convicción propia participaron en los alzamientos populares armados y probaron ser tan capaces como los hombres.

Si las mujeres de las clases bajas no tenían otra alternativa que involucrarse en la Revolución, las mexicanas de las clases alta y media podían no hacerlo. No obstante, al darse cuenta de que la lucha armada era el único medio eficaz para remover de su puesto a Porfirio Díaz, por 34 años dictador de México, estas últimas entregaron sus fortunas a grupos 
revolucionarios. Generalmente actuaban desde la invisibilidad y en silencio, razón por la cual muchas de sus acciones quedaron en la sombra de la historia. La ya mencionada Rose Eleanor King opinaba que las mujeres burguesas vivían en una indolente opulencia, con un orgullo que ignoraba su propia inutilidad. Las exhortaba a respetar a las mujeres de clase baja: " $\mathrm{i} M u j e r e s$ mexicanas educadas que apenas escapan de sus ciegos caparazones, recuerden esto y honren, donde quiera que ella se encuentre, a la soldadera mexicana!" (Oviedo 161). Tras haber gastado sus fortunas, algunas mujeres burguesas se encargaron de medicinas, municiones, ropas, alimentos, correo, equipo militar, así como de espionaje y contrabando de armas. Aprendieron nuevas ocupaciones como despachadoras de trenes, telegrafistas, enfermeras, farmacéuticas, empleadas de oficina, periodistas, editoras de periódicos, maestras y educadoras (Turner 607).

No hemos realizado este breve recorrido por los trabajos que versan sobre las aportaciones de las mujeres a la Revolución Mexicana con el objetivo de identificar a las heroínas nuevas. Fuimos llevados por el propósito de mostrar que las mujeres de todas clases sociales coadyuvaron a este hecho histórico que cambió el rumbo de su país. En este sentido, todas eran revolucionarias, todas eran rebeldes. Si en el caso de las mujeres de la clase baja la rebeldía se manifestó en la lucha por la injusticia social, la de las mujeres educadas de clase media y alta se mostró en el abandono del ámbito familiar y privado, prescrito para ellas por la sociedad patriarcal.

Es paradójico, pero los hombres que lucharon con el sector femenino hombro con hombro y atestiguaron sus acciones, las reconocieron como sujetos históricos, políticos y nacionales en distintos campos del movimiento revolucionario. Frederick Turner afirma que el general Salvador Alvarado escribió en 1918: "Mientras no elevemos a la mujer, nos será imposible hacer patria" (609). Turner también revela que en 1929 el coronel C. J. Velarde señaló que la mujer, independientemente de su clase social, posición económica o creencia religiosa, había llegado a formar una "parte integral, aunque no reconocida, de la valiosa unidad nacional mexicana" (609). Miguel Alessio Robles, el destacado periodista y escritor mexicano, declaró en 1929 que "las mexicanas merecían gratitud eterna por su participación en la liberación de la patria" (Turner 609). Cada una de estas voces masculinas traza para la sociedad mexicana una tarea que hasta ahora no ha sido cumplida: otorgarle a la mujer un lugar merecido en la Historia de México pues, como plantea Elena Poniatowska, en América Latina las mujeres son las grandes olvidadas de la historia. Los libros son la mejor forma de rendirles homenaje. 
PÁGINAS DE UNA VIDA REBELDE

"La Rebelde, Leonor Villegas de Magnón, ... falleció en la ciudad de México el 17 de abril de 1955 ... Su cadáver fue llevado a Laredo, Texas, ... donde reposa en el Panteón Católico" (Villegas 199). Con estas palabras de la pluma de Leonor Villegas Grubbs, la hija de la fundadora de la Cruz Blanca Constitucionalista, finaliza la autobiografía de Leonor, cuyas páginas desvelan la vida de su autora, una de tantas mujeres mexicanas valientes que se involucraron en los quehaceres de guerra. Por tales logros le concedieron cinco medallas, mientras que, entre los años 1910 y 1920, su nombre figuró en numerosos periódicos. En 2010 en su ciudad natal fue inmortalizada con un monumento. Tenían que pasar casi 100 años para que la Revolución Mexicana le hiciera justicia.

De las 26 peticiones que escribió Leonor Villegas de Magnón en el período entre 1920-1955, solicitando la publicación de su único libro, $L a$ Rebelde, todas fueron rechazadas. Para ese entonces contaba con 78 años de edad. Atrás quedó la infancia transcurrida en el idílico mundo aristocrático, entristecida por la muerte de su madre; la educación religiosa recibida en los internados católicos norteamericanos; el matrimonio contraído con Adolfo Magnón, padre de sus tres hijos; los numerosos viajes por Europa y los años de la vida bien acomodada en la capital mexicana, período al que ella referirá como la época de esplendor y riqueza de la burguesía porfiriana. No era una novelista, pero sí colaboró desde 1910 con los periódicos El Progreso, La Crónica y El Radical, apoyando el movimiento armado y afirmando su filiación maderista y luego constitucionalista. Los artículos incendiarios contra la dictadura porfirista que escribía y firmaba con su nombre de soltera eran los primeros pasos en su camino revolucionario. En 1914 fundó la Cruz Blanca Constitucionalista y, junto con otras mujeres que la acompañaron en esta tarea, salvó muchas vidas. Cuando Madero tomó el poder en sus manos, preocupada por conservar la lengua española en la región de Laredo, Texas, donde vivió después de la Revolución, fundó las primeras guarderías bilingües. Con un estilo muy particular y en un tono algo nostálgico plasmó sus recuerdos en papel, entreabriendo así la ventana a su vida y convirtiendo el manuscrito en la única fuente fidedigna sobre su persona. En 1955, tres días después de haber intentado por última vez que se publicara su relato, Leonor Villegas de Magnón murió.

Las razones por las que las editoriales negaban la publicación de $L a$ Rebelde hay que buscarlas en el libro mismo, en su estilo, su género literario, así como en el ambiente que gobernaba en la sociedad mexicana en las décadas posteriores a la Revolución. En el apartado que sigue pretendemos dar cuenta de estos elementos. 
LA ESCRITURA AUTOBIOgRÁficA COMO LA BÚSQUEdA DE UNA IDENTIDAD

Afirmaba Rosario Castellanos que "cuando una mujer latinoamericana toma entre sus manos la literatura, lo hace con el mismo gesto y con la misma intención con la que toma un espejo, para contemplar su imagen" (144). El argumento esgrimido por Castellanos refiere al reflejo del individuo en la escritura, cuando trata de traer al lenguaje sus propias experiencias pasadas, y hace eco con la percepción que tiene Georges Gusdorf sobre la autobiografía: "[E]s el espejo en el que el individuo refleja su propia imagen" (11). De manera tácita, estas definiciones ponen en juego elementos como la forma del lenguaje, el tema tratado, la identidad del autor y del narrador, que Philippe Lejeune también considera para su ya clásica interpretación del concepto un: "relato retrospectivo en prosa que una persona real hace de su propia existencia, poniendo énfasis en su vida individual $y$, en particular, en la historia de su personalidad" (50). La imagen que refleja la escritura, entonces, es certificada por el acto de escribir, mismo que exige la actualización de los recuerdos individuales e íntimos, volviéndolos públicos y compartidos a través del lenguaje. Es una "imagen que, haciendo uso de la memoria, aquel combustible que nos eleva y nos permite volar" (Marina 118), expone los rasgos y las sombras del yo referencial. Durante este encuentro consigo mismo, donde la identidad emerge como el resultado de una creación activa y se ve trastocada por las sombras del mañana, el sujeto da sentido a los eventos pasados, los reordena y los revive desde su posicionamiento en el presente. A tal afirmación identitaria en el texto, es decir, cuando el autor, el narrador y el personaje son la misma persona, Lejeune se refiere como pacto autobiográfico, en el cual también está involucrado el lector. Respecto a esto argumenta: "En efecto, el pacto ... es una forma de contrato entre autor y lector en el que el autobiógrafo se compromete explícitamente no a una exactitud histórica imposible sino al esfuerzo sincero por vérselas con su vida y entenderla" (57). En otros términos, la función del discurso autobiográfico no es decir la verdad, sino aparecer como verdadero.

Cuando Leonor Villegas de Magnón tomó una hoja en blanco, tenía la intención de hacer el pleno uso de su derecho a la memoria, escribir su biografía, inventar su pasado. En la primera hoja escribió "La Rebelde", indicando así al posible lector que el relato que está a punto de leerse se desarrollaría en torno a ella, la acaudalada hija de un comerciante español, y explicando que el título de la portada hace referencia al apodo asignado a ella por su padre el día en que los militares confundieron el llanto de la recién nacida Eleonor con el de un rebelde, oculto en su casa. Efectivamente, las páginas iniciales narran, en primera persona gramatical, 
los acontecimientos de su vida y reconstruyen la realidad social en México en el umbral de los siglos XIX y XX.

Después de haber celebrado el pacto autobiográfico, la voz autorial cambia abruptamente a la tercera persona gramatical, no así la focalización, pues es la misma Leonor quien sigue narrando desde su punto de vista maderista, luego constitucionalista, y quien a partir de este momento y hasta el final del relato alude a su persona como La Rebelde. ${ }^{1}$ Para el lector, tal reajuste no es inesperado, ya que fue advertido desde el inicio: "Ésta es la historia de miles de personas a quienes yo debo justicia y a quienes yo honro. Algunas todavía sirven a su gobierno, luchando silenciosamente y esperando la realización de los sueños de Carranza" (Villegas 3).

La transformación de la voz narrativa modifica también el objeto focalizado, subordinando la representación de los acontecimientos de la vida de la narradora a la de los hechos revolucionarios. Tal movimiento estratégico le permite a la protagonista no solo contarse y volverse visible, sino también poner de relieve a otros, hombres y mujeres que formaron parte de su realidad social. Al posicionar su yo dentro del contexto histórico, donde lo político, lo social y lo personal se funden, la autora se perfila como un ente consciente y responsable cívicamente quien, a través de la escritura, trata de ordenar sus experiencias con el fin de comprender y sacar lecciones de ellas.

A lo largo de este proceso de recuperación del pasado vivido por ella, tarea que implica excavar las distintas formas de la memoria, Villegas aclara al lector que no pretende escribir una historia oficial de los acontecimientos, sino únicamente lo que ella vio, conllevando así a su autobiografía un valor testimonial, del que carece la concepción tradicional, esto es, aquella que ha sido considerada como un género identificado con el sujeto masculino, donde lo que se privilegia es la vida individual de la persona o la historia de su personalidad y no la escritura misma de la subjetividad. Ahora, la tarea narrativa de Leonor consiste en resaltar las aportaciones de las mujeres quienes colaboraron con ella en los eventos revolucionarios sucedidos en la frontera norte y cuyos esfuerzos y sacrificios no fueron reconocidos, según ella, por el gobierno del México posrevolucionario. Respecto a ello, afirma: "Muchas compañeras han muerto y quizá no se les haya hecho justicia, si así es, que este débil esfuerzo inmortalice a las que fueron ejemplo para la patria y que siempre haya almas puras y leales que sepan vivir y morir por ella" (198).

El lector mexicano posrevolucionario, familiarizado con el contexto histórico y social en México al final del conflicto armado y a quien estaba 
dirigida la primera versión del manuscrito, pudo haber asumido que con su obra Villegas de Magnón intenta hacer justicia a las valiosas enfermeras - específicamente aquellas del área de la frontera norte que crearon la Cruz Blanca - que tan patrióticamente defendieron su país, ya que la historia oficial casi borró el recuerdo de su participación en la Revolución Mexicana. En otra parte de su autobiografía Leonor explica una razón más por la que elabora su manuscrito, y es que a través de muchos años oía la voz del Primer Jefe que le decía que escribiera sobre la Revolución.

Por otra parte, al recurrir al uso de la tercera persona gramatical, que es poco habitual en los discursos autobiográficos, Villegas desafía los cánones de este género. Pero esta estrategia narrativa no modifica el pacto de lectura, puesto que el texto sigue siendo leído como referencial. Con esto la narradora logra un matiz impersonal de la narración, se distancia histórica y discursivamente de lo que relata, pues lo que le interesa ahora a la narradora es relacionar los acontecimientos y mencionar nombres:

La Rebelde se ocupaba de tener su red revolucionaria, se comunicó telegráficamente con la señora Guadalupe Bringas de Sonora, quien de una manera extraordinaria se preocupó por los heridos en Guaymas y Cananea. Su esposo era doctor y los dos juntos iban en un tren cuyos carros estaban equipados de lo indispensable para curar y hasta operar a los heridos. Mucho se ha dicho de los valientes generales: Álvaro Obregón Maytorena, Gil, etcétera, pero aún no se ha dedicado ni digo un momento ni siquiera un párrafo a los brillantes hechos de las heroínas revolucionarias. (3)

Otro de los efectos que se logra con el cambio de la voz es la posibilidad de evitar correr el riesgo de engrandecer su papel en el desarrollo de los acontecimientos narrados:

La Rebelde dirigía las actividades sociales que eran la base moral de simpatía y patriotismo; comprendía que era un deber de todos los órganos sanos y puros que integraban la gran familia mexicana coadyuvar con todas sus fuerzas al rápido triunfo de la causa que debería restablecer el gobierno ultrajado de Francisco I. Madero. (74)

De acuerdo a lo anterior, puede entonces afirmarse - retomando las palabras de Clara Lomas, autora de la introducción a la obra de Villegas que el género de memorias noveladas (Villegas xi), que dan vistazo a las luchas de las mujeres, encarceló el relato de Villegas de Magnón en una forma narrativa que históricamente era privilegio de la autoridad, autoría y discurso masculinos, y que ignoraba o negaba esas mismas cualidades 
femeninas, motivo por el cual la obra no representaba interés alguno para los editores. Este primer argumento también esclarece al segundo, al que Leonor explica en el siguiente fragmento de su poema titulado Soy una triste peregrina: "En las chozas, en los templos, en los palacios, en los campos de batalla, pides esa limosna (de amistad sincera) y nada encuentras, ¿y por qué? ¿Tan sólo por el delito de ser mujer?" (Villegas xxxii). Finalmente, está el hecho de que el título La Rebelde, obra que pretende inscribirse en los terrenos del género autobiográfico, no corresponde a los objetivos que en diversas ocasiones plantea la autora, insistiendo en que "no pretende hacer un panegírico o alabar la grandiosa obra redentora de este personaje [Carranza], pues eso lo harán las plumas más autorizadas que la de ella. Sólo desea rendir humildemente un débil pero sincero tributo a su memoria. ‘'Duerme en paz, valiente luchador!’” (198; énfasis mío).

LAS REBELDES: UNA ESCRITURA PALIMPSESTUOSA

Publicada en 2011, la novela de Mónica Lavín Las rebeldes relata la historia de las mujeres que durante la Revolución Mexicana se unieron al ejército constitucionalista en calidad de enfermeras y periodistas, principalmente. El relato se lleva a cabo mediante dos voces narrativas, una de ellas pertenece al personaje ficticio de Jenny Page, una periodista norteamericana quien, durante el acto de contar tanto sus propias experiencias revolucionarias como las de sus compañeras, tiene cincuenta y nueve años. En su juventud se escapó de la casa de sus padres huyendo de la autoridad patriarcal - "yo se la había declarado [la guerra] a la casa donde los otros decidían por mí" (Lavín 68) dirá años después, al justificar su partida - y para acompañar a su tía, Lily Long, a realizar la tarea de enfermera y escribir sobre ello en los periódicos: "La tía Lily me tenía bajo su cargo. Arguyó que, además, yo escribiera para La Crónica. 'Tienen que saber que existimos,' insistió a Leonor cuando la miró, perpleja por llevar a una chica americana que quería participar en la revuelta mexicana" (66). En una de esas misiones se encuentra con un soldado federal mexicano herido en la batalla y se enamora de él; el sincero amor que nace entre ellos, representantes de bandos antagónicos, culmina con la separación, dejando una marca dolorosa en la vida de la periodista.

La segunda voz es la de un narrador omnisciente. Su tarea es describir, desde fuera de la historia, las acciones, los pensamientos y las actitudes de Leonor Villegas de Magnón, la heroína principal de la novela. Es a través de la mirada de esta instancia narradora que contemplamos a la fundadora de la Cruz Blanca Constitucionalista en los contextos íntimos y privados, observamos su conducta en las reuniones con los generales, nos enter- 
amos de las inquietudes respecto a su relación con el esposo, de quien vivía separada a causa de las tareas que cada uno realizaba.

Desde el primer encuentro del lector con la obra, se pone en evidencia que esta establece una fuerte y significativa relación con el texto de Villegas de Magnón. Los títulos son el elemento intertextual importante que de un modo sintético apuntan al contenido de ambos objetos verbales. Cuando el proceso de lectura se pone en marcha, el lector se encuentra con constantes alusiones al texto de Villegas Magnón, empezando por la aclaración del sobrenombre que se presenta casi literalmente: “ ¿Y recuerdas, papá, por qué me llamabas la Rebelde? Te has cansado de repetir cómo entraron a nuestra casa y, al oír mi llanto de bebé, creyeron que era un rebelde escondido. Y que tú me mostraste irritado, porque atentaban contra un inocente: 'Ésta es la Rebelde', los avergonzaste. Se fueron sin hacernos nada" (44).

De la misma manera que Villegas de Magnón, Lavín nos acerca a las realidades sociales mexicanas al inicio del siglo pasado. En este caso, la voz que nos cuenta sobre la vida cotidiana en ambos lados del Río Grande es la de Jenny, y es a través de sus sentidos que el lector percibe el ambiente:

Cruzar el puente internacional no es tan fácil como antes. Quién diría que, cuando se celebraba el onomástico de George Washington, no se pedían papeles y unos y otros andábamos por las calles alborotados. Veíamos el desfile de caballos, escuchábamos a las bandas de este lado y del otro del río, se bebía agua de jamaica o de limón de los vitroleros en la plaza. Se jugaba lotería, había cohetes y otros fuegos artificiales por la noche. Era una fiesta americana, pero la celebrábamos a la mexicana. Nadie preguntaba quién era de dónde. Se respiraba México en las calles de Laredo y a mí me gustaba ir a la fiesta. Todos los de la high school practicábamos organizando puestos de kermés, que si tacos de machacado o de frijol con chorizo.

La cita anterior muestra también cómo la narradora hace uso del lenguaje, ese puente comunicativo entre el recuerdo y la memoria, para exteriorizar sus evocaciones. Lo que está implícito en el trabajo de memoria que lleva a cabo Jenny es el reconocimiento de la tradición americana a la que los mexicanos también hacen suya. Por pertenecer a los tiempos pretéritos, esta tradición ya es ausente en el presente de la enunciación y cobra vida solo mediante la imaginación de la que relata. Por otra parte, el fragmento citado anteriormente muestra que toda memoria establece una relación significativa con los espacios y lugares, puesto que el acto de recordar los resignifica y les otorga nuevos sentidos. ${ }^{2}$ Se observa que, para Jenny, la ciudad de Laredo no es un simple lugar geográfico y es que la afectividad 
con la que ella elabora la descripción arriba mencionada constituye un elemento discursivo estratégico que le permite definir y legitimar su propia identidad.

A diferencia de la forma del título La Rebelde, con el que Villegas de Magnón hace referencia a sí misma, Lavín utiliza el mismo calificativo referencial pero en plural y con letra minúscula, indicando así que la obra tratará sobre varias mujeres, cuyos destinos se asemejan al de Leonor. Efectivamente, a través de la voz que el narrador omnisciente le cede a Leonor, el lector se entera de que las muchachas que se unieron a la Cruz Blanca "lo hacen porque quieren, porque apoyan a los constitucionalistas y están dispuestas a salir de sus casas, dejar la comodidad y ayudar a dar alivio" (96). Inmediatamente después de esclarecer las razones que las mueven a ser parte de estos acontecimientos, la heroína utiliza la forma verbal inclusiva, implicando que lo dicho es válido también en su caso: "Eso es lo que podemos hacer las mujeres en esta guerra" (96).

Ningún cambio revolucionario es percibido de la misma manera por los miembros de la sociedad. A través de los sutiles diálogos entre el personaje principal y las mujeres a las que ella acude para solicitar todo tipo de apoyo, se manifiesta que no todas ellas comparten el punto de vista de Villegas Magnón: "No es que no nos interese la Revolución, señora Magnón, ni nos parezca loable su labor - se atrevió Lolis Benavides -, pero no podemos apoyar el que las mujeres abandonemos a nuestras familias por estar en esta lucha" (190). Estar en la lucha significaba rebelarse, oponer resistencia al papel tradicional de la mujer que la sociedad patriarcal había esperado que cumplieran:

Las chicas se encargaron de correr la voz de aquella primera impresión que les habían dado Leonor Villegas, Lily Long y Jovita Idar. Se informaron de quién era cada una y, cuando supieron que el marido de la presidenta vivía en la ciudad de México y que ella había dejado a sus tres hijos en Laredo, además de invertir su fortuna en uniformes, medicinas y viajes; que Lily Long, siendo norteamericana, andaba pisando este suelo donde no tenía vela en el entierro, y que Jovita Idar era una periodista revoltosa, les pareció que estaban algo zafadas. Las malas lenguas llegaron a decir que si una mujer dejaba marido e hijos y no cuidaba su dinero, es que había perdido la cabeza. (189)

Insistía Paul Ricoeur, siguiendo a Aristóteles, en el carácter paradójico de la memoria. Una de estas paradojas se halla en el hecho de que la memoria reconoce y al mismo tiempo niega la naturaleza secuencial del tiempo (22). Es precisamente en ella en la que se basa el relato literario, donde el presente es el presente de varios tiempos, fenómeno que permite los 
juegos temporales en el relato. Uno de estos casos se puede observar en el fragmento en que Jenny llega a la estación de trenes de Laredo, en la cual décadas atrás abordó el tren que la llevaría junto con otras enfermeras a El Paso. Al encontrarse allí en el presente del acto de relatar y al observar la estación ya reconstruida, en la mente de la narradora surge el encadenamiento de las imágenes de todas las estaciones de trenes que le tocó conocer durante su juventud revolucionaria: la de Ciudad Juárez, de Chihuahua, de Torreón, de Saltillo. Al mismo tiempo que experimenta estos recuerdos, emergen en la imaginación de la periodista las caras expectantes y jubilosas de ella y de sus amigas, así como los uniformes que tenían puestos. La verbalización de estas imágenes, que son el producto del proceso rememorativo, las trae hacia el presente, las actualiza, pero al mismo tiempo indica que son del pasado:

Vengo aquí para escribir sin la pluma, para sentarme en la banca y recordar mi figura esbelta, el mandil que llevábamos en el equipaje, la cofia y la banda azul que nos distinguía como Cruz Blanca. La llevamos puesta en el brazo izquierdo, por encima del codo, sobre nuestros vestidos de viaje. (65)

Lavín nos presenta a Leonor Villegas de Magnón desmitificada, más real y con el mayor sentido común. Tras gastar su fortuna, la protagonista de Lavín sí piensa en su propio futuro y se atreve a confiar en el apoyo de Carranza, pues este la apreciaba y estaba enterado de los sacrificios de Villegas en nombre de la Revolución. Sin embargo, para enfatizar que tales pensamientos eran incómodos para la Rebelde, Lavín nos los presenta a través de la voz del narrador omnipresente:

Carranza, estaba segura, no la habría de olvidar. Sintió pudor por aquel reclamo. Sería una de muchos que esperaban su tajada en el nuevo orden. Lo admitía: quería estar en el reparto del pastel. Carranza bien conocía su lealtad y su capacidad de organización y trabajo, su entrega. ¿Acaso no había dejado familia y tranquilidad esos dos años? (292)

La misma estrategia narrativa se utiliza para nombrar todos los sacrificios hechos por la protagonista, con el fin de enfatizar de que estos no fueron reconocidos en vida y así justificar el deber que siente la autora de homenajear a esta singular mexicana:

La presidenta de la Cruz Blanca Constitucionalista trabajó en la oficina de Veteranos, haciendo trabajos de escritorio: Esa señora que está allí frente a la máquina, la del pelo cano, es Leonor Villegas, la Rebelde. Fue mi jefa y la de muchas 
mujeres que auxiliamos a los heridos de la Revolución, a los heridos de Carranza o de Pablo Gonzáles, de Jesús Dávila o de Francisco Villa. Tenía fortuna: el rancho San Francisco y las tierras de su padre Joaquín en Tamaulipas; la casa de los almacenes Villegas en Quentin y Flores en Laredo, y la casa victoriana, con su veranda y sus ventanas salientes, sus torreones en Salinas y Victoria, también en Laredo, la casa de Nuevo Laredo y lo que heredó su madrastra Eloísa. Invirtió su herencia en la Cruz Blanca. Convenció a otros de que cooperaran y, para ello, puso su parte. (293)

Desde el interior de la novela Jenny Page afirma que, al escribir la historia de la Cruz Blanca, está cumpliendo la voluntad de su amiga, Leonor Villegas, la voluntad expresada en la carta que acompañaba su manuscrito. La epístola decía: "Escriba esta historia ... Si este paquete la encuentra con salud y ánimo, es necesario que alguien escriba esta historia que no ha sido contada ni publicada ni es visible porque no es de las batallas ganadas, perdidas, de las traiciones y el poder que va cambiando de dueño. Escríbala, por favor, por mí, Jenny. Escriba" (12). El trabajo creativo que Jenny desarrolla se ve rodeado por dudas, inquietudes e interrogaciones: “A alguien le interesaba un grupo de enfermeras y médicos acompañando a los constitucionalistas durante la Revolución? ¿0 me pasaría como a Leonor? ¿Tendrá un manuscrito sin escucha?" (310). La periodista llega a terminar la historia, ya que "[l]os muertos mandan. Si no, no estaría yo, la viuda de Balm, la Jenny Page encanecida, cumpliendo esta tarea" (310). He aquí una alusión más al texto autobiográfico de Villegas, quien explica con la misma frase en tercera persona gramatical la razón por la que debe rendir homenaje a Carranza: "Bien decía Vicente Blasco Ibáñez: 'Los muertos mandan'. Aun no siendo escritora, a La Rebelde le consumía un deber sagrado de dejar huellas en las arenas movedizas del tiempo, recordando al varón mexicano que fue símbolo de HONRADEZ" (Villegas 125; mayúsculas en el original).

Las memorias siempre se confrontan con el olvido, y en la obra de Lavín la memoria individual de Leonor sirve para cuestionar la falta de información sobre la aportación de las mujeres mexicanas a los hechos tormentosos de la Revolución. El ejemplo más claro de esta lucha contra la desmemoria lo muestra el episodio en el cual la heroína reflexiona sobre el asesinato de Carranza, el Primer Jefe, como le solía decir, y sobre los cambios que esta muerte le trajo a su propia vida:

[Leonor] buscaría en su memoria los días intensos de aquella cruzada de los constitucionalistas. Escribiría sus memorias. Eso era lo que ahora podía hacer. Ésa era su batalla. Dar testimonio de la grandeza de los hombres con que compartió la 
revuelta y no condenar al olvido a las mujeres valerosas que la secundaron. Ahora estaba más segura que nunca de que los muertos mandaban. (332)

Ahora bien, si desde su inicio el texto de Lavín mostraba elementos intertextuales, al final revela explícitamente, y a través de la voz de Jenny, su dimensión palimpsestuosa, misma que se origina a la hora de deconstruir a la obra La Rebelde y conocer todo el material existente que le permitió a la escritora comprender la multifacética imagen de Leonor Villegas:

Hay mucha indiscreción en andar mirando los papeles que alguien atesora en su vida. Al menos eso me pasa a mí con la caja de Leonor Villegas. Con esos dos manuscritos, uno en inglés, otro en español, La Rebelde y The Rebel, y las cartas de las editoriales que los rechazaron. Uno más escueto, el otro más acucioso en la información. Con errores históricos, tal vez, pero escritos con el rescoldo de la memoria, antes de que el tiempo enfriara el ímpetu y acartonara los hechos. Y luego encontrarse los telegramas, las cartas de Carranza ... Hay muchas fotos dedicadas a Leonor, le muestran respeto, a veces salpicado de cariño, los generales Murrieta, Caballero, González, Carranza. (309)

El fragmento anterior evidencia que el armado de sentido de la imagen de la Rebelde requiere también de una estrategia de lectura diferente, una que exige un lector activo, un cómplice capaz de relacionar la información proporcionada por la escritora y articular su propia visión de la protagonista. Después de concluir nuestras reflexiones analíticointerpretativas sobre la novela Las rebeldes, podemos enumerar los rasgos principales de esta escritura palimpsestuosa. ${ }^{3}$ Se trata de la obra que se caracteriza por el uso de distintas voces narrativas, entre las cuales existen algunas que reflejan la conciencia individual de los narradores; constituye la forma innovadora de escribir sobre los hechos históricos, rebelándose contra la forma tradicional de novela histórica, cuyo discurso, en términos de Noé Jitrik (182), no tiene ningún propósito de alcanzar la verdad, pues se destaca por ser confirmatorio, reduplicador y no contradictorio respecto al histórico oficial. A esto habría que añadir la subversión extendida a todos los niveles y otros aspectos novelísticos (temática, personajes, estrategias discursivas y narrativas), sin olvidar la construcción de figuras femeninas que, debido a lo antes mencionado, se desplazan desde la periferia hacia el centro de la narración.

LA MIRADA QUE HABLA Y LA PALABRA QUE DIBUJA

Las dos creaciones literarias que nos ocupan en este artículo se caracte- 
rizan por la presencia en ellas de fotografías, imágenes congeladas que desde su invención hasta prácticamente la segunda mitad del siglo pasado fueron consideradas como documento social (Freund 8). Aparecen en las portadas, adelantando en gran medida el sentido de las obras y constituyendo sus paratextos. Así, por ejemplo, en el caso del libro de Villegas de Magnón, la fotografía en blanco y negro está debajo del título La Rebelde. En ella se aprecia un grupo de músicos tocando frente al vagón de un tren, encima del cual se encuentra una docena de personas armadas. La nota en el extremo izquierdo inferior de la foto explica: "Banda del Gral. Munguía", mientras que de la que se ubica del lado opuesto se ve que la imagen fue tomada por Eustasio Montoya, el fotógrafo oficial de la Cruz Blanca. De esta manera, para un lector familiarizado con la historia de México, la palabra (el título) y la imagen, en una situación de igualdad, producen un mensaje sobre el contenido del libro.

Las obras de Villegas de Magnón y de Lavín contienen respectivamente veinte y seis fotografías, mismas que formaban parte del archivo personal de la fundadora de la Cruz Blanca. Como una persona pragmática y culta, conocía muy bien el valor histórico de estos documentos visuales, por lo cual repetía varias veces a Montoya que "las fotografías son historia, y usted no debe dejar que nadie tenga un negativo o vender las fotografías. Las fotografías son mi propiedad personal. Yo pagué por los materiales" (Villegas 120). La mayoría de las imágenes representan los fragmentos de la vida cotidiana de las enfermeras. Nos describen desde la particularidad del lenguaje visual sus acciones, las personalidades con quienes convivían y los lugares que han recorrido. Por lo anterior, podemos argumentar que estas imágenes fotográficas funcionan como texto visual, esto es, actúan como una narración contada por el fotógrafo, quien las realizó con la intención de permitirle a su observador acceder a una realidad pasada (Cid 137; Riego 175).

A pesar de que en ambas obras se utilizan las mismas fotografías, el uso que les dan las autoras es distinto. Las que encontramos en La Rebelde cuentan con las notas informativas sobre el lugar, la fecha y las personas que se aprecian en ellas. Más que ilustrar la historia narrada por la autora, fungen como documentos que gozan de una gran carga de presentismo histórico que - debido a su veracidad - entra en la categoría de la llamada verdad histórica, pues como afirma Montserrat Huguet (24), lo que aparece en una fotografía sin duda sucedió. La fotografía aporta la evidencia, la prueba del acontecimiento, autentifica el mundo visible y preserva la información que tenemos de él. El hecho de ser concebida como documento y como testimonio visual hizo que durante la Revolución Mexicana, el primer conflicto bélico cubierto por fotógrafos, las imágenes 
fotográficas se convirtieron en protagonista periodístico principal, cuya presencia abrumadora arrinconó el texto escrito en los periódicos.

En el caso de la novela de Lavín, las fotos se sitúan en los lugares estratégicos del texto para visibilizar lo narrado y complementarlo. El capítulo Un pañuelo, por ejemplo, inicia con las reflexiones de Jenny Page sobre los objetos que encuentra en la caja recibida de Leonor. Entre fotos, recortes, telegramas, notas con cuentas de hoteles, compras de vendas y cartas, pensaba toparse con algún objeto íntimo, no obstante, "lo más personal era aquella foto de Leonor y tía Lily en un día de campo con Carranza y con Luis Cabrera y Gustavo Espinoza Mireles, como aparece escrito al reverso" (29). Inmediatamente después de esta frase se presenta la imagen, en la cual efectivamente se observan las figuras de dos mujeres $\mathrm{y}$ tres hombres sentados en lo que parece ser un bosque, compartiendo alimentos. De esta manera, la fotografía fragmenta el texto verbal, dando entrada a la construcción de un relato interno híbrido, donde la palabra ofrece estructura y anclaje al significado de la imagen. En el resto de los casos del uso de las fotos en la obra es similar. Esta oscilación entre lo verbal y lo visual posibilita al lector un acercamiento particular a la obra y con el mundo en ella contenido.

Por lo anterior, se puede argumentar que el escritor y el fotógrafo acuden al mismo recurso: el vocablo, mientras el uno describe una imagen con mil palabras, el otro describe mil palabras con una imagen. En el texto de Lavín, el fragmento que ejemplifica este trabajo de memoria es el siguiente: "La cabeza de herido en mi regazo. La camisa hecha girones a la altura del codo, el codo sin codo, la sangre detenida por la otra manga de la camisa que la tía Lily había apretado en lo que quedaba del brazo" (77). Aquí, a través del uso de los enunciados nominales, la autora logra describir el desplazamiento de la mirada de Jenny, quien desde el presente del acto de enunciación reproduce la imagen de uno de los heridos que ella atendió.

Debemos a Georges Didi-Huberman el argumento de que la imagen tiene más de memoria y más de porvenir que el ser que la mira. Los personajes de Lavín son conscientes de este poder de las imágenes de registrar hitos de la memoria, de dejar la constancia para las futuras generaciones de que lo plasmado en ellas realmente aconteció. Con la clara intención de dejar huella de su paso por los sucesos revolucionarios, contratan al fotógrafo Eustasio Montoya y describen su función así: "Deja memoria de nuestra actividad: quiénes somos, cómo trabajamos, cómo nos movemos de un sitio a otro, con qué generales tratamos. Sin memoria no hay nada" (69).

Entonces, cuando Eustasio toma las fotografías, lo hace con su propia 
mirada, la que contiene su yo y en la que interviene su memoria; pero por contener las imágenes de las enfermeras y de las personas a las que atienden, la fotografía se convierte para ellos en un lugar de memoria por excelencia, hasta tal punto que el pasado se convierte en aquello que se ve. De este modo, al crearse como fruto de la memoria individual, cuando se difunde, la fotografía pasa a formar parte de una experiencia de memoria común compartida.

Sin duda alguna, las creaciones literarias que constituyeron el objeto de nuestro estudio forman parte del legado cultural mexicano. Escritas por mujeres, se vuelven un acto de resistencia y de desafío a los discursos oficiales de sus épocas, que por razones diversas ocultan las páginas importantes de nuestro pasado nacional. Para llenar estos numerosos vacíos, las y los escritores escriben libros, creando técnicas narrativas innovadoras y haciendo uso de la imaginación que se halla en la esencia de su oficio. Como hemos observado, al dar cabida a distintos tipos de lenguajes, la literatura establece relaciones profundas con la memoria, misma que acude al relato para poder (re)estructurar nuestro pasado y encontrar en él las explicaciones de nuestra situación presente.

Instituto de Ciencias Sociales y Humanidades de la Benemérita Universidad Autónoma de Puebla

\section{NOTAS}

1 Dirigido por Francisco I. Madero entre 1909 y 1910, el maderismo fue el primer movimiento que conformó la Revolución Mexicana; su objetivo principal fue la regeneración democrática de México a través del sufragio efectivo y la no reelección de los funcionarios públicos. Las fuerzas constitucionalistas se organizaron en 1913 en los estados de Chihuahua, Sonora, y Tamaulipas, tenían por objetivo el levantamiento de los campesinos de todo el norte del país y para quienes la Revolución significaba la perspectiva de tierra, el movimiento atrajo también a la pequeña burguesía democrática de provincia, a maestros, artesanos, agricultores medianos y a sectores burgueses locales que antes habían apoyado al maderismo y veían en Carranza, con su instinto de gobernador, un freno a la revolución campesina.

2 En este caso se trata de la memoria cultural que junto con la memoria comunicativa forma parte de la memoria colectiva. Esta funciona de dos formas: una que guarda la información sobre los orígenes y otra que se ocupa de los datos o eventos biográficos. La primera se manifiesta en rituales, bailes, formas de ornamentación, vestimentas, adornos, estampillas, paisajes, entre 
otros, que cumplen funciones mnemotécnicas. En cambio, la memoria biográfica se basa en la interacción social (Assmann 34).

3 El término de la escritura palimpsestuosa es de Gérard Genette y se refiere a las múltiples formas de recreación y de reescritura artística que logran integrar en el texto los mitos, leyendas, cuentos y acontecimientos históricos.

OBRAS CITADAS

ASSMAnn, JAn. Religión y memoria cultural. Buenos Aires: Ediciones Lilmod, 1992. CAN DAU, J Ö L. Antropología de la memoria. Buenos Aires: Nueva Visión, 2006.

CAS T L Lanos, Rosario. Mujer que sabe latín. México: Fondo de Cultura Económica, 2003.

CH ORBA, CARRIE CHRistine. Mexico, from Mestizo to Multicultural: National Identity and Recent Representations of the Conquest. Nashville: Vanderbilt UP, 2007.

CID , A LFRED o. "La semiótica en la lectura de la fotografía". Ética, poética y prosaica: ensayos sobre fotografía documental. Ed. Ireira de la Peña. México: Siglo XXI, 2008. 133-152.

Didi-huberman, georges. Ante el tiempo. 2ª edición. Buenos Aires: Adriana Hidalgo Editora, 2008.

EAKIn, PA U J J h n. Fictions in Autobiography. Studies in the Art of Self-Invention. Princeton: Princeton UP, 1985.

FREUND, GIS È LE. La fotografía como documento social. 8ª edición. Barcelona: Gustavo Gili, 1999.

Genet TE, GÉRA RD. Palimpsestos. La literatura en segundo grado. Madrid: Taurus, 1989.

GUSD ORF, GEORGES. “Condiciones y límites de la autobiografía”. La Autobiografía y sus problemas teóricos. Estudios e investigación documental. Ed. Ángel Loureiro. Barcelona: Anthropos, 1991.

HUGUET, M ON TSERRAT. "La memoria visual de la historia reciente". La mirada que habla (cine e ideologías). Ed. Gloria Camarero Gómez. Madrid: Akal, 2002. 8-22. HUYSSEN, ANDREAS. "En busca del tiempo futuro". Puentes 1.2 (2000): 1-21. J I T R I K, N OÉ. Suspender toda certeza. Antología crítica (1959-1976). Buenos Aires: Biblos, 1997.

LAVín, Mónica. Las rebeldes. México: Debolsillo, 2013.

LEJEUNE, PHILIPPE. El pacto autobiográfico y otros estudios. Madrid: Megazul, 1994. LOMAS, C LARA. "Las mujeres revolucionarias y la prensa alternativa en la frontera". Introducción. La rebelde. Por Leonor Villegas de Magnón. Houston: Arte Público Press, 2004. xv- lxii.

MA R I A, J J É A n T o io. Teoría de la inteligencia creadora. Barcelona: Anagrama, 2000. 
m l loy, silvia. Acto de presencia. La escritura autobiográfica en Hispanoamérica. México: Fondo de Cultura Económica, 1996.

OVIEDO Y PÉREZ DE TUDELA, Rocío. "Mujeres de la Revolución Mexicana/Mujeres ante la Revolución Mexicana”. Narrativa de la Revolución Mexicana: realidad histórica y ficción. Eds. Antonio Lorente Medina y Javier de Navascués. Madrid: Verbum, 2011. 147-166.

P ONIA T O WS KA, ELENA. "Las mujeres son las grandes olvidadas de la historia."

Entrevista de Jéssica Nieto. El Mundo 8 marzo 2011. S.pag. Web.

PONS, MARÍA CR IS TINA. Memorias del olvido. La novela histórica de fines del siglo XX. México: Siglo XXI, 1996.

pozuelo yvancos, José María. Poética de la ficción. Madrid: Síntesis, 1993.

Ricoevr, PAu l. La memoria, la historia, el olvido. México: Fondo de Cultura

Económica, 2004.

RIEG O, BERNARD O. La construcción social de la realidad a través de la fotografía y el grabado informativo en la España del siglo XIX. Santander: Universidad de

Cantabria. 2001.

SCHAEFER, ClA Ud A. Textured Lives: Women, Art, and Representation in Modern Mexico. Tucson: The U of Arizona P, 1994.

TURNER, FREDERICK C. "Los efectos de la participación femenina en la Revolución de 1910". Historia mexicana 16.4 (1967): 603-620.

VILlegas de magnón, LeONor. La rebelde. Houston: Arte Público Press, 2004. volóshinov, valentín. El Marxismo y la filosofía. Los principales problemas del método sociológico en la ciencia del lenguaje. Madrid: Alianza, 1992. 